\title{
A method for track fusing using data association in naval combat system
}

Un método para fusión de trayectoria usando asociación de datos en el sistema de combate naval

Eunmi Oh ${ }^{1}$

\begin{abstract}
In today battlefield multi-sensors installed on naval ship are acquiring too much information. Information is used through naval combat system to improve reaction capability to threat more quickly and precise. For acting to threat, we have to make a decision whether same ones what each target from multi sensor and execute track fusion according to result of judgment. So in this paper, we propose the track fusion method using track's varied information. We predicted and estimated the target state based on dynamic information using data association filter so made valid measurement area what is assumed that track exists. This algorithm can set up the criterion what is adaptive current status of track. Second we selected track among existing tracks in valid area by attributing weighting. The weight considers track's information like identification, category and so on. We would like to execute more precisely track fusion through this fusion algorithm.
\end{abstract}

Key words: Combat Management System, Track Fusion, Data Association, Tracking Filter.

\section{Resumen}

Actualmente los sensores múltiples del campo de batalla instalados en una embarcación naval están adquiriendo demasiada información. La información es usada a través del sistema de combate naval para mejorar la capacidad de reacción y para amenazar de manera rápida y precisa. Actuar para amenazar, se debe tomar una decisión sobre cuál de los objetivos del sensor múltiple y ejecutar la fusión de trayectoria acuerdo el resultado del criterio. En este artículo, proponemos el método de fusión de trayectoria usando información variada de rastreo. Pronosticamos y estimamos el estado del objetivo en información dinámica usando filtro de asociación de datos lo cual hizo válida la medida de área que es asumida como trayectoria existente. Este algoritmo puede establecer el criterio cuál estado actual de adaptación de trayectoria. En segundo lugar, se eligió la trayectoria entre las existentes en un área válida mediante la atribución de ponderación. La ponderación considera la información de la trayectoria tal como: identificación, categoría, entre otros. Se podría ejecutar la fusión de trayectoria de manera más precisa a través de un algoritmo de fusión.

Palabras claves: Gestión de sistemas de combate, fusión de trayectoria, asociación de datos, filtro de trayectoria.

Date Received: October 16 $6^{\text {th }} 2014$ - Fecha de recepción: Octubre 16 de 2014

Date Accepted: January 13 $3^{\text {th }} 2015$ - Fecha de aceptación: Enero 13 de 2015

${ }^{1}$ Research engineer. Lignex. Seul, Korea. Email: eunmi.oh@lignex1.com 


\section{Introduction}

Naval combat management (CMS) system receives information from multi-sensors and weapons, tactical data communication mounted on ships. It plays a role as brain of battle ship by monitoring battlefield, executing threat evaluation of detected tracks to help command decision of commander, acting to threat tracks. Therefore, in naval ship target detection from multi-sensors, detected target tracking, command decision and action for engagement is constantly repeated.

Today sensor capability is growing day by day, and consequently a lot of the high quality target information is obtained together. So we should start from the correct identification of the target in order to respond effectively to the threat. For this reason, the naval combat system has been required a technique for fusion tracks from each sensor are determined same target. This fusion technology is very important because the threat evaluation and engagement are executed on the basis of a fused target.

The condition for determining that the same target considers the various feature of track like identification (hostile, friend, neutral...), form (point track, bearing track...), category (air, surface, subsurface ...), position and maneuver information. In real battlefield situation, some attributes of target (identification, category, form, etc..) doesn't easily change but target state (position, maneuver) changes each time. Because prediction of track state is difficult so precise track fusion technology what is adaptive with maneuver is required.

In this paper, we propose a method for track fusing by estimate track state variable using a dynamic filter. First, validation gate of reference target is stochastically calculated using data association. (The same target from other sensors is assumed to exist in the validation gate) And then a measurement that is determined to be equal to the reference target among measurements are located in validation gate is selected. The validation gate is calculated by predicted state variable from dynamic filter and measurement of sensor.
In chapter II $\sim$ IV, related theories and simulation result are suggested, in the last chapter a conclusion is showed.

\section{Background}

Track management is one of the main data processing algorithms of the CMS. This has the functions to process and fuse incoming data from multi sensors and communication systems. In today as mission type is changing solo to join, importance of the track processing is gradually being raised. Condition of the track fusion that has been operating in the combat system of the ship is as follows [1]:

1. Track attributes (Identification, category, type, etc.) match

2. Track position - distance between the candidate tracks have to below criteria.

But if the distance between the candidate tracks is configured as a constant, it can't reflect the battlefield situation. Therefore a lot of studies for track fusion are being carried out and research on data fusion is especially active.

Data fusion is to fuse acquired measurements from multi sensor and to trace trajectory of fused tracks using data association. This is method for obtaining a better tracking performance in the clutter environment. In data association method, track and measurement means like this:

- Measurement : acquired target information at the current time.

- Track: estimated measurement with traceability

And Data fusion that estimates track state variable (position, maneuver) exists in different forms.

1. Measurement fusion : measurements from multi sensor are fused in fusion center and then estimate track based on the fused measurement. (fusing $\rightarrow$ generating track)

2. Track to Track fusion : Local tracks are created by estimating track from each sensors. And 
then when between local tracks are determined to same, track fusion is executed.(generating local track $\rightarrow$ fusing)

To do the measurement fusion must be assumed that the measurements come from same target. On the other hand in track to track fusion we determine whether the local tracks is same track of target, after that fuse. Most of sensor mounted ship transmits measurements with traceability. So CMS have only to confirm that each track of multi sensors is same target. Therefore requires modification of data fusion, in this paper we propose a method for track fusing by making a decision as same target using data association methods.

\section{Track Management in CMS}

Track management in CMS is to manage many type of track is composed source track, system track, tactical track. Source track is measurement from sensor. It is raw data. System track is a fusion of source tracks of each sensor. Tactical track is generated from fusion between system track and data link track The fusion is executed with the rules. The procedure of track management is in the following picture.
Tactical tracks that are created by the same procedure as above figure are represented on a chart of tactical display and used in tactical operation as top-level track. Tactical track information is automatically updated according to sensor update. But modification or deletion of some track information could occur by the operator. The fusion is very important function in the track management because tactical operates based on the fused track (tactical track).

Types of sensor(source) to acquire tracks are different from each other ship and track information is also different, too. Thus, the fusion is performed by using the common information. The types are as follows.

- Position (Latitude, Longitude, Altitude or X, Y, Z)

- Maneuver (Velocity, Course)

- Bearing

- Track Form (Point, Bearing)

- Track Identification (Hostile, Friend, Neutral, Pending, Unknown)

- Track Category (Air, Surface, Subsurface, Land)

Track fusion takes place using information such as above and the fusion conditions are as following.

Fig. 22. Procedure of track management.

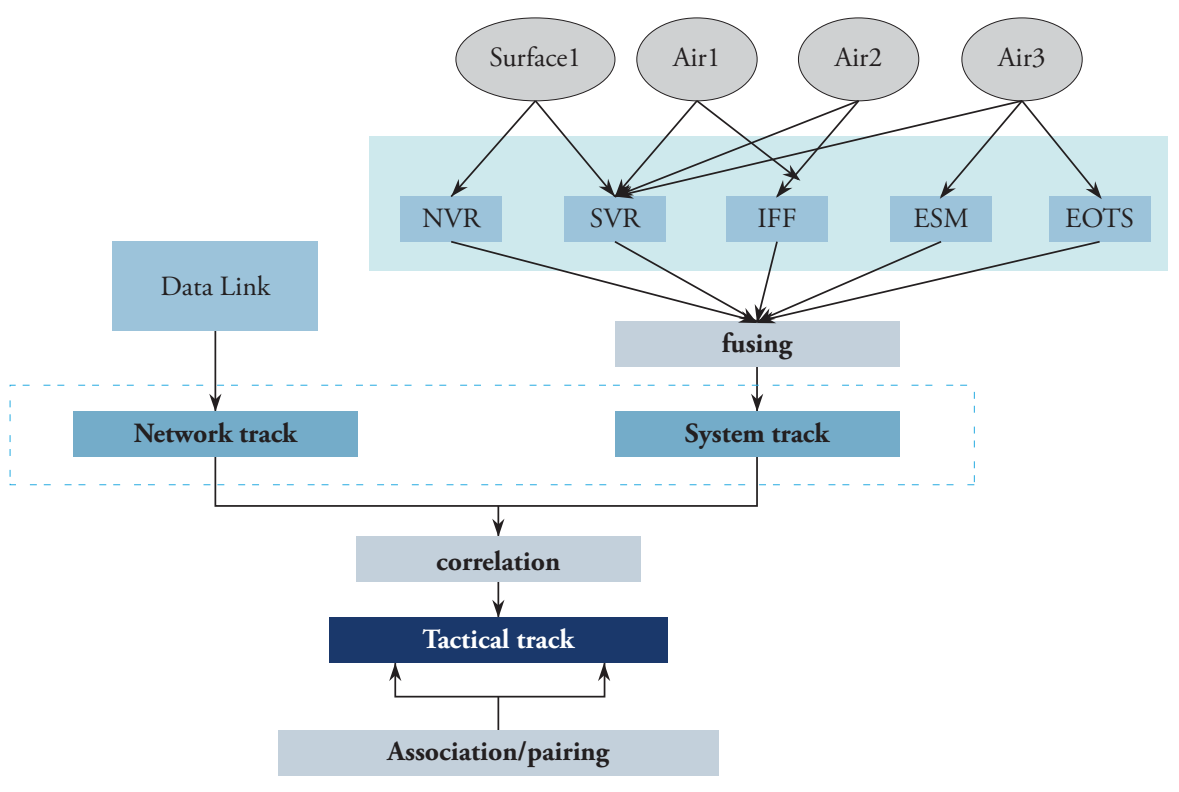


1. The sensors (sources) of tracks have to be The fusion different from each other.

2. Forms of tracks have to be same.

3. Categories of tracks have to be same.

4. Identifications of tracks have to be allowed conflict,

5. The distance between tracks has to be less than criteria.

If candidates for fusion satisfy the all condition such as above, the fusion could be performed based on the unique value assigned to each sensor. The information of the sensor with the highest value becomes the representative information of the fused track.

On the other hand, when fused track is judged that is same track no longer, the defusion could take a place. The conditions of defusion are below and if fused track satisfy any of them, the defusion can be executed.

1. When conflict of the tracks (to form a fused relationship) identification is generated.

2. When the distance between the tracks (to form a fused relationship) increases.

As mentioned in the introduction, some attribute of track (type, form, identification, etc.) aren't easily changed but because the position or maneuver information changes every time track, distance between fused tracks may can't be the same each time for update.

So this paper would like to propose a new method about conditions relating to the distance in order to increase the accuracy of fusion.

Fig. 2. Track fusion.

Fig. 3. Track defusion.

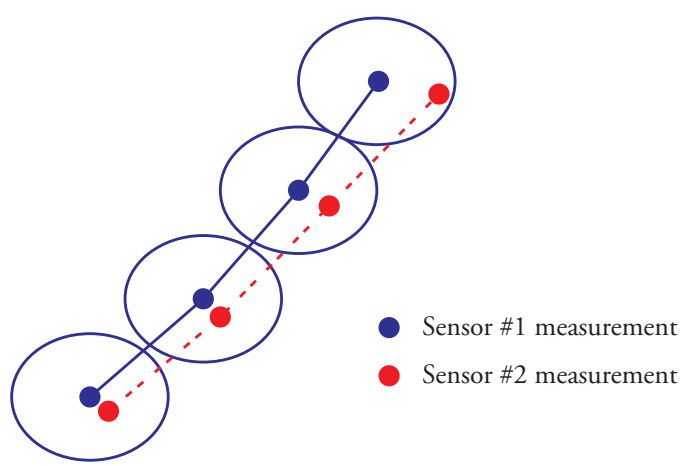

When the track is located within the validation area of other track.

\section{The defusion}

When the track moves out of the validation area of other track.

The validation area is set adaptively to the situation in the track using the method used by the data association and the concerned theory and methods will be suggested in the next chapter.

\section{The validation area calculation}

Data association method is to select a measurement what is determined as target from a number of measurements and to combine with trajectory of target in clutter environment. At this time the measurements have to be located within validation area.

The validation area is an area having a probability of presence of target and generated on the basis of estimated state variable by the tracking filter. Because the track fusion of CMS is to determine as same target, this paper would suggests the fusion method by applying concept of validation area.

For calculation of the validation area tracking filters are used and it is based on the Kalman Filter [2]. Kalman filter is an algorithm that uses a series of measurements observed over time, containing noise

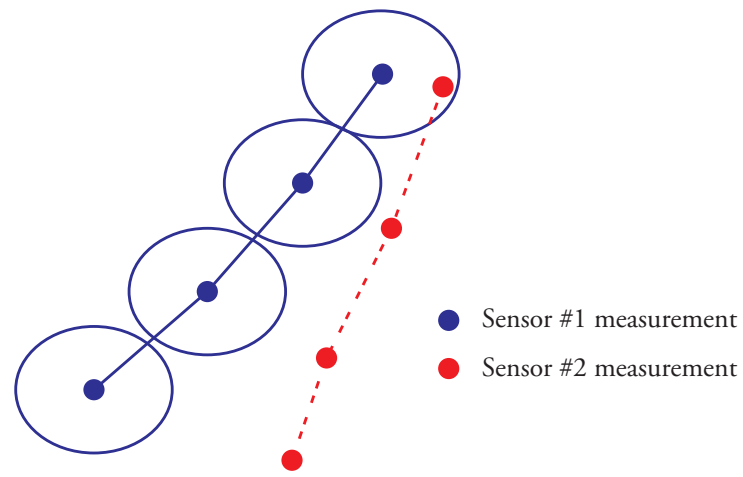


and other inaccuracies, and produces estimates of unknown variables that tend to be more precise than those based on a single measurement alone (Wikipedia). The Kalman filter has numerous applications in technology likes Radar, robotics, etc. Its algorithm is composed 2 steps.

- Prediction : predict the state variables at the present time $(k)$ on the basis of updated state variables in the previous time $(k-1)$

$$
\text { - Outputs : } \bar{X}_{k}, \bar{P}_{k}
$$

- Update : estimate the state variables on the basis of predicted state variables and measurement at the present time $(k)$

$$
\text { - Outputs : } \hat{X}_{k}, \hat{P}_{k}
$$

$X_{k}$ is a state variable and includes position, velocity and acceleration and the like. Also $P_{k}$ is a error covariance matrix at time $k$. The whole loop of the Kalman filter is shown in the following below figure.

Fig. 4. Procedure of Kalman filter.

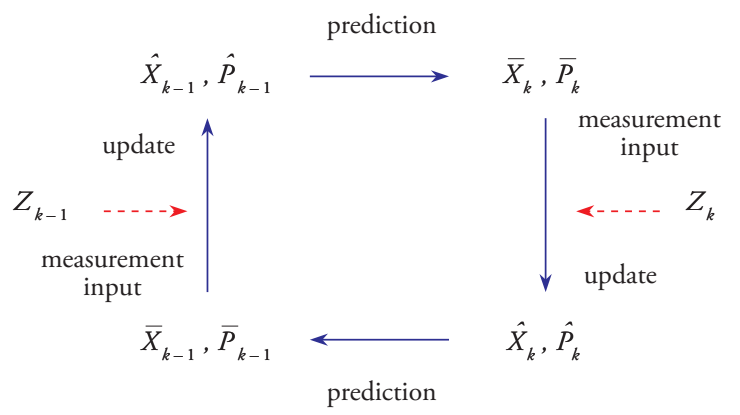

Specific information for estimating the state and error covariance value is the same as Fig -, and then in this paper, we present a method to drive the validation area measured from the data association by applying the Kalman filter.

The validation area is formed with predicted position as a center at present time $(k)$ and predicted position is calculated from updated state at previous time $(k-1)$. The validation area is an ellipsoid and could be presented like this.
Fig. 5. Kalman filter.

$$
\begin{aligned}
& \bar{X}_{k}=\phi_{k} \hat{X}_{k-1} \\
& \bar{P}_{k}=\phi_{k} \hat{P}_{k-1} \phi_{k}^{T}+Q_{k}
\end{aligned}
$$

$$
\begin{aligned}
& \bar{K}_{k}=\bar{P}_{k} H_{k}^{T}\left(H_{k} \bar{P}_{k} H_{k}^{T}-R_{k}\right)^{-1} \\
& \hat{X}_{k}=\bar{X}_{k}+K_{k}\left(z_{k}-H_{k} \bar{X}_{k}\right) \\
& \hat{P}_{k}=\left(I-K_{k} H_{k}\right) \bar{P}_{k}
\end{aligned}
$$

The validation area is formed with predicted position as a center at present time $(k)$ and predicted position is calculated from updated state at previous time $(k-1)$. The validation area is an ellipsoid and could be presented like this.

$G_{\gamma}(k)=\left\{v_{k} \mid v_{k}^{T} S_{k}^{-1} v_{k} \leq \gamma\right\}$

$v_{k}\left(v_{k}=z_{k}-\bar{z}_{k}\right)$ is a measurement residual as Gaussian distribution. Its mean is 0 and covariance is $S_{k}$.

$S_{k}\left(S_{k}=H_{k} \bar{P}_{k} H_{k}^{T}+R\right)$ is a residual covariance and $\sqrt{\gamma}$ is gate size of validation area. Also the volume of the validation area with the $\mathrm{n}$-dimensional is derived as follows.

$V_{G}=C_{n}\left|S_{k}\right|^{\frac{1}{2}} \gamma^{\frac{n}{2}}$

$n$ is the dimension of the measurement, the value becomes like

$C_{1}=2, C_{2}=\pi, C_{3}=\frac{4}{3} \pi$

in accordance with the $n$.

Distance between the predicted position $\left(\bar{z}_{k}\right)$ and measured position $\left(z_{k}\right)$ is determined by NDS (normalized distance squared) D what is calculated by using residual and residual covariance. NDS D is derived as follows at time $k$ 
$D_{k}=v_{k}^{T} S_{k}^{-1} v_{k}$

NDS D has been reflected in the current status of the target because it is calculated by normalized value considering the error between predicted position and measured position. So when NDS $\mathrm{D}$ is less than criteria, the measurement can be assumed that came into the validation area.

As an example, the result of validation area was shown. Two-dimensional Model that is the basis for the fusion was set like this:

- The initial position: $(+15000 m,+15000 m)$

- The initial velocity: $(-70.71 \mathrm{~m} / \mathrm{s},-70.71 \mathrm{~m} / \mathrm{s})$ and then from 20 second will start up in the other direction.

- Sampling time: $1 \mathrm{sec}$

- Measurement error: $v_{z}-N\left(0,(15 m)^{2}\right), v_{\gamma}-N\left(0,(15 m)^{2}\right)$

- Filter for estimating: Kalman filter

Fig. 6. The validation area.

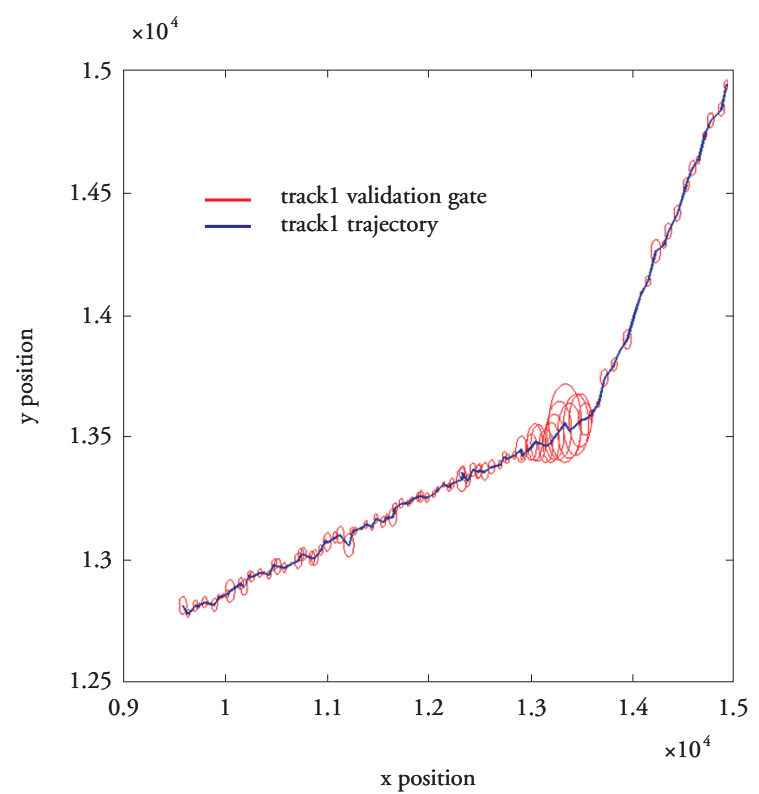

As a result, the validation area was expended because of increasing of difference between measured position and predicted position by unexpected turn at 20 second.

Like this because the validation area is gained by reflecting the estimated target's status in order to apply this method, target estimation(tracking) should be robust. Today various data association method being studied to improve performance of tracking and detailed information will be presented in the next chapter.

\section{Data association}

In clutter environment, data association [3-5] method is to predict and estimate of target state by finding a measurement of the target. This method using the target information can be divided into three.

1. Utilizing the signal strength of measurements

2. Utilizing the distance of measurements

3. Utilizing both the signal and the distance of measurements

But measurements what is considered to estimate have to be located within validation area. The details are shown in Table 1.

In addition studies being carried out for tracking maneuvering vehicles like IMM (Interacting Multiple Model) [6] algorithm or using the track information as weight to calculate probability. Therefore, such tracking filters will be applied effectively in combat systems of managing track information by multi-sensors.

\section{Conclusion}

The combat management system not just to manage the raw data for target from each sensor, it should fuse and manage through to determine as the same target. It is important function to assist mission execution. So in this paper, a new method for track fusing was proposed. The method is to apply the validation area of data association. In data association the validation area is an area having a probability of presence of target and generated on the basis of estimated state variable by the tracking filter. Many type of tracking filter was presented and a simulated result was included in the previous chapters. Making the validation area is adaptive because it is reflects the current situation of the 
Table 1. Type of tracking filter.

\begin{tabular}{|c|c|c|}
\hline Type & Name & Description \\
\hline Signal base & SNF, PSNF & $\begin{array}{l}\text { Considered as a target the measurement that have a greatest signal } \\
\text { strength in the validation area }\end{array}$ \\
\hline Distance base & NNF, PNNF & $\begin{array}{l}\text { Considered as a target the closest measurement to the center of the } \\
\text { validation area. }\end{array}$ \\
\hline \multirow{3}{*}{$\begin{array}{l}\text { Signal and } \\
\text { distance-base }\end{array}$} & IPDAF & $\begin{array}{l}\text { Based on signal strength and distance from center of validation area } \\
\text { of measurement, each measurement's probability that comes from } \\
\text { real target is calculated and estimate is executed by considering the } \\
\text { probability. }\end{array}$ \\
\hline & MPDAF & $\begin{array}{l}\text { Measurements are sorted to ascending order of distance from the } \\
\text { center of validation area. And then apply this results are as weight } \\
\text { to probability and a measurement what have highest probability is } \\
\text { selected as a real target. } \\
\text { (the probability that comes from real target consider both signal } \\
\text { strength and distance) }\end{array}$ \\
\hline & HPDAF & $\begin{array}{l}\text { Measurements are sorted to descending order of signal strength. And } \\
\text { then apply this results are as weight to probability and a measurement } \\
\text { what have highest probability is selected as a real target. } \\
\text { (the probability that comes from real target consider both signal } \\
\text { strength and distance) }\end{array}$ \\
\hline
\end{tabular}

target. So this method using data association may be useful because the consideration target of the current battlefield status. But if prediction and estimation of track are failed, wrong validation area is made also. Therefore, robust tracking performance is required.

Also not robust tracking performance, but other factors should be considered further. First, one is time synchronization between the sensors because acquisition cycle is different. Second, operational time of the tracking filter should be considered for the track to be managed as a maximum at the same time.

In addition to these limitations, It is necessary to continuous research about the applicability of the tactical element and other information of track to improve the fusion accuracy.

\section{References}

[1] SMITH, D. and SINGH, S., "Approaches to Multisensor Data Fusion in Target Tracking: A Survey," Knowledge and Data Engineering, IEEE Transactions on, Vol 18, Issue. 12, 2006.
[2] SALMOND, D., "Target tracking: introduction and Kalman tracking filters", Target Tracking: Algorithms and Applications, IEE, Vol.2, Oct. 2001.

[3] Y. BAR-SHALOM and T. E. FORTMANN, "Tracking and Data Association", Academic Press, New York, 1988.

[4] KIRUBARAJAN, T., Bar-Shalom, Y, "Probability Data Association techniques for target tracking in clutter", IEEE Transactions on AES, Vol.38, Issue. 2, April 2002.

[5] A.T. ALOUANI and T.R. RICE, "On optimal synchronous and asynchronous track fusion", SPIE, Opt. Eng., Vol. 37, Issue 2, 427, 1998.

[6] JAWARD, M.H. and KADIRKAMANATHAN, V. "Interacting multiple models for single-user channel estimation and equalization", ICASSP '01, IEEE International Conference on, Vol.4, 2001. 